\title{
BMJ Open Prevalence and risk factors for overweight and obesity: a cross- sectional countrywide study in Burkina Faso
}

\author{
Seydou Kaboré, ${ }^{1,2}$ Tieba Millogo (D) ,1,3 Joseph Kouesyandé Soubeiga, ${ }^{1,4}$ \\ Hermann Lanou, ${ }^{1,3}$ Brice Bicaba, ${ }^{1,5}$ Seni Kouanda (D) ${ }^{1,3}$
}

To cite: Kaboré S, Millogo T, Soubeiga JK, et al. Prevalence and risk factors for overweight and obesity: a crosssectional countrywide study in Burkina Faso. BMJ Open 2020;10:e032953. doi:10.1136/ bmjopen-2019-032953

- Prepublication history for this paper is available online. To view these files, please visit the journal online (http://dx.doi. org/10.1136/bmjopen-2019032953).

Received 20 0ctober 2019 Revised 15 0ctober 2020 Accepted 19 October 2020

Check for updates

(C) Author(s) (or their employer(s)) 2020. Re-use permitted under CC BY-NC. No commercial re-use. See rights and permissions. Published by BMJ.

For numbered affiliations see end of article.

Correspondence to Professor Seni Kouanda; skouanda@irss.bf

\section{ABSTRACT}

Objective The objective of this study was to determine the prevalence and predictors of overweight and obesity in Burkina Faso using a population-based countrywide sample. We hypothesise that there is a significant burden related to overweight/obesity in Burkina Faso.

Design Secondary analysis of a population-based countrywide cross-sectional study.

Setting Burkina Faso, all the 13 regions including both rural and urban residential areas.

Participants 4800 participants of both sexes, aged between 25 and 64 years.

Main outcomes Overweight and obesity using body mass index cut-off levels of the WHO.

Results The prevalence of overweight and obesity in Burkina Faso were $13.82 \%$ (95\% Cl: 12.25 to 15.55$)$ and $4.84 \%$ (95\% Cl: 3.99 to 5.86), respectively. Among men, the proportional odds of overweight/obesity increase with urban residency $(p<0.001)$, greater age $(p<0.002)$, marital status different from single $(p \leq 0.007)$ and decrease with current smoking $(p=0.009)$. Among women, the proportional odds of overweight/obesity increase with urban residency $(p<0.001)$, primary educational level $(p=0.01)$, high total blood cholesterol level $(p<0.001)$ and high fasting blood glucose level $(p=0.02)$, and decrease with current smoking $(p<0.001)$.

Conclusion Our study showed that nearly one person out of five in the adult population of Burkina has an abnormal weight status with women being more affected than men. Urban residency is a consistent risk factor in both men and women. Alcohol consumption and education were associated with an increased odds in only women. Overnutrition needs to be recognised as an important public health issue in Burkina Faso and nutrition interventions need to be reshaped to account for it.

\section{INTRODUCTION}

Obesity is defined as an abnormal or excessive accumulation of body fat, due to an energy imbalance between intake and expenditure. ${ }^{1}$ It is a major risk factor for many noncommunicable diseases (NCDs) and a real public health threat in the world..$^{23}$ In 2015 , high body mass index (BMI) contributed to
Strengths and limitations of this study

- To our best knowledge, this is the first nationwide study on obesity and overweight in Burkina Faso with a country-level representative sample.

- Outcomes measurements were carried out following international standards through the WHO STEPwise approach to non-communicable diseases measurement and prevention.

- This is a cross-sectional study, which hampers our ability to derive causal inferences from the reported data.

- The socioeconomic status, a known relevant variable, was not measured in the primary study.

- Being overweight may not necessarily equate to being an obese person to be, particularly in a setting where food insecurity is common.

4.0 million deaths, which represented $7.1 \%$ of the deaths from all causes. ${ }^{4}$

Obesity, a well-known phenomenon in developed countries, is increasingly common in low-middle-income countries, affecting both children and adults. ${ }^{245}$ In the Eastern Mediterranean region, the prevalence of obesity increased in adults from $15.1 \%$ in 1980 to $20.7 \%$ in 2015 . It increased from $4.1 \%$ to $4.9 \%$ in the same period among children. $^{6}$ In sub-Saharan Africa (SSA), overweight/obesity factors accounted for 266768 deaths, representing 3.3\% of allcause mortality. ${ }^{7}$ Thus, in low-income and middle-income countries, the association of overweight/obesity with one or more nutritional deficiencies is often observed, especially among women and known as double burden of malnutrition. ${ }^{8}$ However, data from the literature report that excess weight can largely be avoided, and prevention involves the identification and control of modifiable risk factors. ${ }^{25}$ These factors have been widely described in the literature. These are mainly 
related to behaviour and/or knowledge (inadequate diet, inactivity, alcohol consumption), sociodemographic factors (place of residence, socioeconomic status) and clinical and metabolic factors (total cholesterol level, HDL (High Density Lipoprotein), triglycerides). ${ }^{59-11}$

However, the factors vary between countries, depending on eating habits and sociocultural practices. ${ }^{2}$ This variability of factors suggests a relevance of country-specific studies to identify context-specific and relevant risk factors in order to better guide and align the policies and strategies aiming to address the raising burden of obesity.

The studies conducted so far on factors associated with overweight or obesity in low-middle-income countries were often conducted in urban areas, ${ }^{12-16}$ hospitals $^{1718}$ and secondary and high schools. ${ }^{19-21}$ There are few nationally representative data on obesity in most subSaharan African countries. ${ }^{922}$ This scarcity of nationally representative data on the burden and risk factors for overweight/obesity is an obstacle to engaging countries in the design and implementation of adequate public health interventions.

Our study intends to fill this gap by providing more complete data on the prevalence and the risk factors for overweight and obesity, through a secondary analysis of data from the STEPS (STEP wise approach to surveillance) survey carried out in Burkina Faso in 2013.

\section{METHODS}

\section{Study setting}

Our study was conducted in Burkina Faso, a landlocked Sahelian country in the heart of West Africa. The country is divided into 13 regions, 45 provinces and 351 municipalities. In 2013, the population was estimated at 21478529 inhabitants. The majority of the population lives in rural areas, with agriculture and livestock as main activities. ${ }^{23} 24$

In terms of health, the country is still facing endemicepidemic diseases, especially malaria, measles, cerebrospinal meningitis, acute respiratory infections, diarrheal diseases and HIV/AIDS infection. ${ }^{25}$ The prevalence of acute malnutrition in children under 5 years was estimated at $8.1 \%$ in $2019 .{ }^{26}$

Mortality due to NCDs is increasing rapidly in the same time; it was estimated that $33 \%$ of all death cases were due to NCD in $2016{ }^{27}$

\section{Type of study}

We carried out an analytical cross-sectional study consisting of a secondary analysis of the data from the 2013 STEPS survey in Burkina Faso.

\section{Study population}

The study population of the survey was composed of adults of 25-64years who have been living in the national territory for at least 6 months before the survey. Persons with an inability to answer questions (cognitive impairment) were excluded from the primary study. Pregnant women were excluded from our analysis.

\section{Sampling and statistical power}

The enumeration areas (EAs) from the 2006 General Population and Housing Census, updated in 2010 during the Demographic and Health Survey conducted in Burkina Faso (EDS-BF, 2010), were used as sampling frame. The STEPS survey was carried out on a nationally representative sample of 4800 households with 20 households per EAs, giving 240 EAs for the whole country. The sample was stratified in each of the 13 administrative regions to provide an adequate representation of the urban and rural areas. This stratification took into account the distribution of the population depending on the urban $(22.7 \%)$ and rural environment $(77.3 \%)$ in Burkina Faso, giving 54 EAs for urban area and 186 EAs for rural areas across the country. Within each stratum, a three-stage cluster sampling was done as recommended by the WHO for STEPS NCD risk factors screening surveys.

At the first stage, the choice of clusters or enumeration zones by administrative regions was made by a systematic draw with proportional probability to the size of the EAs.

At the second stage, a household count in each of the selected 240 clusters at the first stage provided a list of households from which a sample of 20 households was selected using a simple systematic random sampling with an Excel spreadsheet.

At the third level, the choice of individuals within households was made randomly. Once a household is selected, the interviewer creates a listing (sampling frame) of all eligible adults of both sexes aged between 25 and 64 years in the household. The listing includes the following variables: name, gender, relationship to the household head and age. Once the listing is created, each eligible member is assigned a unique number. Then using a randomised response table (Kish table), a particular member is chosen for the interview. ${ }^{28}$ In each household, an individual of 25-64 years living in the household was drawn to participate in the survey.

The STEPS survey took place from 26 September to 18 November 2013 and enrolled a total of 4800 individuals. Out of the 4800 participants, we excluded 152 pregnant women, 153 with missing data (on height and/or weight) and 23 without sampling weights. The sample size for our secondary analysis comprised 4472 persons (see figure 1 for study inclusion process). With this final sample size and assuming a prevalence of obesity of $4.5 \%$, our study has a statistical power of $86.6 \%$ to detect an association of a magnitude of 1.5 with the type I error rate $\alpha$ of $5 \%$.

\section{Data collection}

The collection of data was carried out by nurses, graduate medical and nurse students. The data collection consisted in face-to-face interviews of selected participants using standardised questionnaires and physical and biochemical measurements. The data collection tools were pretested before they were used at the national level.

Data collection teams were closely supervised by a team of supervisors composed of statisticians, epidemiologists and clinicians. 


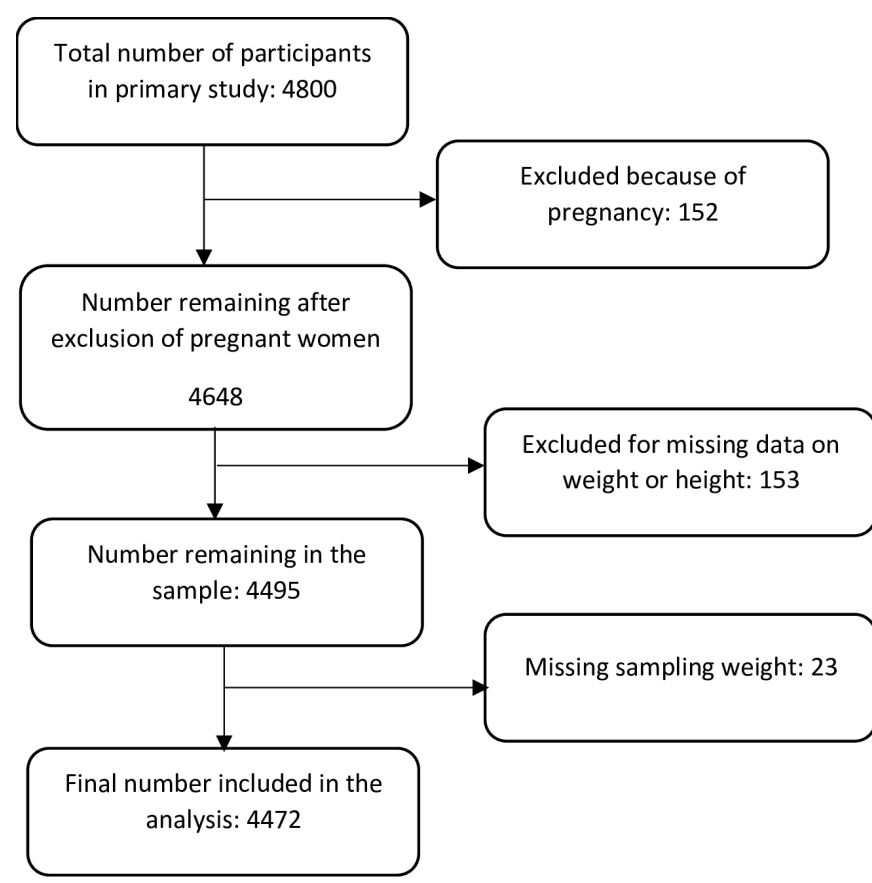

Figure 1 Flow diagram of the study participants. This figure shows the criteria that were used to select the study participants in our study and the numbers that were affected by these criteria and the final sample size of the study.

Height measurement (in $\mathrm{cm}$ ) was made in a standing or lying position, using a portable measuring board, on the participant without shoes and hat. The weight (in $\mathrm{kg}$ ) was measured using an electronic weighing scales (SECA) placed on a stable and even surface, the person lightly dressed, shoes off and in a standing position.

The total cholesterol and blood glucose levels were measured using a CardioCheck PA SILVER kit that performs all these measurements using a capillary whole blood sample. Further details on the STEPS survey are available elsewhere. ${ }^{29}$

\section{Study variables}

We used BMI to define general obesity. The BMI was calculated dividing the weight $(\mathrm{kg})$ by the size $\left(\right.$ in $\left.^{2}{ }^{2}\right)$ and then used to define undernutrition $\left(\mathrm{BMI}<18.5 \mathrm{~kg} / \mathrm{m}^{2}\right.$ ), normal $\left(18.5-24.99 \mathrm{~kg} / \mathrm{m}^{2}\right)$, overweight $(25.0-29.99 \mathrm{~kg}$ / $\left.\mathrm{m}^{2}\right)$ and obesity $\left(30 \mathrm{~kg} / \mathrm{m}^{2}\right)$ in accordance with the WHO recommendations. ${ }^{2}$ We also used waist circumference to compute central obesity with the cut-off points of $94 \mathrm{~cm}$ in men and $80 \mathrm{~cm}$ in women. ${ }^{30}$

Independent variables included age, marital status, place of residence, occupational activity, educational level, total cholesterol level, fasting blood glucose, smoking, alcohol consumption, the type of fat most commonly consumed and the intensity of physical activities. Some variables were recoded using specific cut-points of grouping (see table 1).

\section{Statistical analysis}

The predictive variables were selected based on the literature. We carried out stratified gender-based analyses. The Fisher's test was used to evaluate associations between the dependent variable and independent qualitative variables. We calculated crude proportional odds ratio and adjusted proportional odds ratios (APORs) using an ordinal logistic regression model. The dependent ordinal variable has four categories: underweight, normal, overweight and obese. The covariates selection in the multivariable analysis was based on epidemiological plausibility and literature review. All the analyses were weighted to account for the study design, and we computed robust standard errors to account for the clustered nature of the data. The proportional risk assumption and the overall

Table 1 Recoding of exposure variables

\begin{tabular}{|c|c|}
\hline Variables & Categories \\
\hline Age groups (years) & '25 to 34 ', ' 35 to 44 ', ' 45 to 54 ', ' 55 to 64 ' \\
\hline Education level & 'None', 'primary', 'secondary and higher' \\
\hline Occupational status & 'Employed', 'self-employed', 'unemployed', 'homemakers' \\
\hline Total cholesterol level & Normal (<5.2 mmol/L); high cholesterol ( $\geq 5.2 \mathrm{mmol} / \mathrm{L})$ \\
\hline Daily alcohol consumption & $\begin{array}{l}\text { Male : none }(0 \mathrm{~g}) \text {, low }(0.01-39.99 \mathrm{~g}) \text {, medium }(40-59.99) \text {, high ( } 60 \text { and over) } \\
\text { Female : none }(0 \mathrm{~g}) \text {, low }(0.01-19.99 \mathrm{~g}) \text {, medium }(20-39.99) \text {, high ( } 40 \text { and over) }\end{array}$ \\
\hline Fat intake & 'None', 'vegetable oil', ' butter, lard or fat, margarine' \\
\hline Physical activity & $\begin{array}{l}\text { High-intensity activity: high-intensity activities require an energy expenditure greater } \\
\text { than } 6 \text { metabolic equivalent of tasks (METs). Examples include soccer playing, hole } \\
\text { digging, regular swimming and farming. } \\
\text { Moderate-intensity activity: moderate-intensity activities require an energy } \\
\text { expenditure of approximately } 3-6 \text { METs. Examples include cleaning, vacuuming, } \\
\text { polishing, gardening and cycling at a regular pace or horse riding. } \\
\text { Low-intensity activity: refers to persons who do not meet the above classifications. } \\
\text { Here are included people with limited and no physical activity. }\end{array}$ \\
\hline
\end{tabular}


Table 2 Demographic and behavioural characteristics of study participants

\begin{tabular}{|c|c|c|c|}
\hline \multirow[b]{2}{*}{ Variables } & \multicolumn{2}{|l|}{ Population } & \multirow[b]{2}{*}{ Total } \\
\hline & Male n (\%) & Female n (\%) & \\
\hline \multicolumn{4}{|l|}{ Residence } \\
\hline Rural & $1769(74.48)$ & $1710(70.30)$ & $3479(72.28)$ \\
\hline \multicolumn{4}{|l|}{ Age groups (years) } \\
\hline $35-44$ & $560(28.21)$ & $573(37.65)$ & $1133(27.91)$ \\
\hline $45-54$ & $424(20.22)$ & 404 (18.49) & $828(19.31)$ \\
\hline $55-64$ & $306(13.48)$ & $228(10.40)$ & $534(11.86)$ \\
\hline \multicolumn{4}{|l|}{ Education level } \\
\hline None & $1623(72.93)$ & $1832(81.16)$ & $3455(77.27)$ \\
\hline \multicolumn{4}{|l|}{ Marital status } \\
\hline Single & $254(11.04)$ & $68(3.24)$ & $322(6.93)$ \\
\hline Cohabiting/married & $1879(85.74)$ & $1963(88.06)$ & $3842(86.96)$ \\
\hline Divorced/widowed/separated & $87(3.21)$ & $216(8.70)$ & $303(6.10)$ \\
\hline \multicolumn{4}{|l|}{ Occupational status } \\
\hline Employed & $178(6.68)$ & $71(3.44)$ & $249(2.92)$ \\
\hline Self-employed & $1945(86.12)$ & $1188(50.40)$ & $3133(67.32)$ \\
\hline Unemployed & $87(4.51)$ & $54(2.44)$ & $141(3.42)$ \\
\hline Homemaker & $13(0.70)$ & $936(43.72)$ & 949 (23.34) \\
\hline
\end{tabular}

Prevalence of overweight and obesity

goodness of fit of the final models were checked before the results were reported. All the analyses were based on complete data analysis (missing data were ignored in all analyses). All analyses were carried out using the Stata V.13.1 software.

\section{Patient and public involvement}

Patients or the public were not involved in the design, or conduct, or reporting, or dissemination plans of our research.

\section{RESULTS}

\section{Background characteristics of the study sample}

The sociodemographic characteristics of the individuals of the sample are presented in table 2. Participants of the 25-34 age group were in majority with $40.92 \%$. There were 2249 women, which represents $52.6 \%$ of the participants. Participants with no educational level accounted for $72.93 \%$ among men against $77.17 \%$ among women. The majority of the individuals were married/living in couple $(86.96 \%)$.

As shown in table 3 , the prevalence of overweight and general obesity in the sample were respectively $13.82(95 \%$ CI: 12.25 to 15.55 ) and 4.84 (95\% CI: 3.99 to 5.86). The prevalence of general obesity was higher among women $(\mathrm{p}<0.0001)$ and among urban residents $(\mathrm{p}<0.0001)$. However, the proportion of overweight people did not significantly differ between women and men. Among all age groups, obesity was more prevalent in the age group $35-44(p<0.0001)$. The prevalence of obesity also varies across administrative regions (results not shown). The prevalence of central obesity was respectively $6.33 \%(95 \%$ CI: 5.11 to 7.81 ) and $34.50 \%$ (95\% CI: 31.12 to 38.97 ) in men and women, with significant rural versus urban difference in both sexes $(\mathrm{p}<0.001)$.

\section{Risk factors for obesity and overweight Among men}

In multivariable analysis, significant predictors of overweight and obesity among men included place of residence, physical activity, age, marital status, alcohol, tobacco and fat consumption. Men living in urban areas were around three times proportionally more likely to be at least overweight as compared with those living in rural areas (APOR: 2.84, 95\% CI: 1.90 to 4.23 ). The odds of being overweight or obese was lower within the 25-34 age group as compared with $35-44$ and $45-54$ years. Men aged 35-44 years were 1.4 times proportionally more likely to be overweight or obese (APOR: 1.4, 95\% CI: 1.00 to 1.90). Compared with single men, men living in unions 
Table 3 Prevalence of underweight, overweight and general obesity among study participants

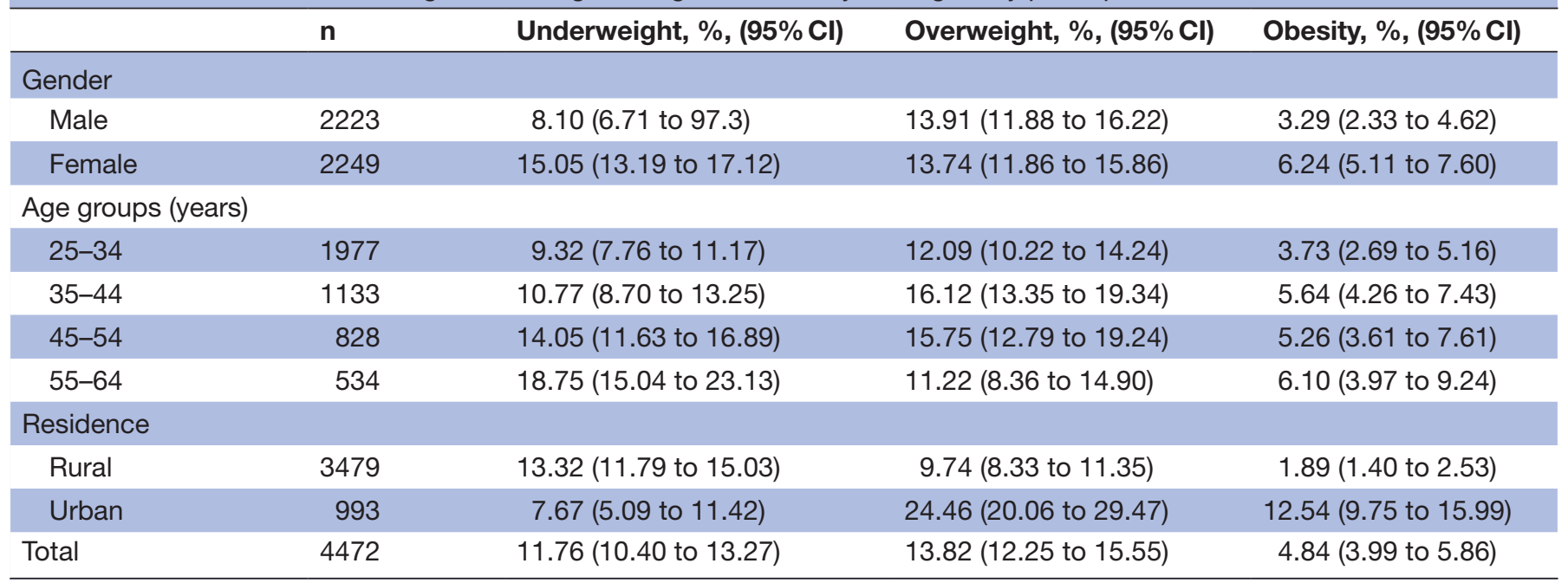

and those who are widowed or divorced were having higher proportional odds of being overweight or obese (APOR: $1.62,95 \%$ CI: 1.09 to 2.42 and APOR: $1.83,95 \%$ CI: 0.76 to 4.39 ). The current consumption of tobacco reduces by nearly half the proportional odds (APOR: $0.53,95 \%$ CI: 0.37 to 0.74 ). No significant difference was found between former and second-hand smokers and men who had never smoked. The report of the consumption of butter, lard or margarine as the most often type of fat was associated with more than $30 \%$ proportional odds reduction (APOR: 0.62, 95\% CI: 0.39 to 0.97 ). The practice of physical activity was also associated with lower odds of overweight/obesity with the odds reduction increasing as the intensity of the physical activity increases (APOR: 0.68, $95 \%$ CI: 0.44 to 1.04 and APOR: $0.62,95 \%$ CI: 0.42 to 0.93$)$.

\section{Among women}

Among women, significant risk factors included urban residence, current tobacco consumption, educational level, the type of occupation and fat consumption. Urban residential status was associated with around threefold increase in the proportional odds of obesity or overweight (APOR: 2.67, 95\% CI: 1.89 to 3.78) as compared with rural residence. Being of primary school education level increased nearly two times the proportional odds of overweight or obesity (APOR: 1.80, 95\% CI: 1.26 to 2.57) as compared with those who have not been at school (no education). The proportional odds of being at least overweight was lower among current tobacco smokers compared with non-smokers (APOR: 0.42, 95\% CI: 0.29 to $0.60)$. As compared with wage earners, women who were self-employed and those who were homemakers were less likely to be overweight/obese (APOR: $0.45,95 \%$ CI: 0.24 to 0.87 and APOR: $0.40,95 \%$ CI: 0.21 to 0.77 ). The report of butter/lard or margarine as type of fat often consumed was associated with lower odds of overweight/ obesity (APOR: $0.67,95 \%$ CI: 0.46 to 0.99 ).
The results of the multivariable analysis are presented in table 4.

\section{DISCUSSION}

\section{Prevalence of overweight and obesity}

The overall prevalence of overweight was relatively high in our study, with no significant difference between men and women. Studies in Africa have also found similar prevalence between both sexes. ${ }^{22} 31$ However, some authors reported higher proportion of overweight among men. ${ }^{32-34}$ The prevalence of obesity in our study was around 5\% with disparities found across regions.

The prevalence of obesity was higher among women. Several other studies also reported higher prevalence of obesity among women. ${ }^{9} 103536$ Hormonal effects, especially among older ages, women's maternity and lifestyle and certain cultural conceptions may be contributing to this higher burden of obesity among women. ${ }^{37}$

\section{Factors associated with obesity}

Living in urban areas and current tobacco consumption are factors associated with obesity or overweight among both genders. van der Sande et al in Gambia ${ }^{9}$ also noted that risk in urban areas was about three times higher than in rural areas (OR: 2.86, 95\% CI: 1.89 to 4.35). Abubakari et al in a meta-analysis of studies conducted in $\mathrm{SSA}^{11}$ also noted that the risk was higher in urban areas (OR: 2.70, 95\% CI: 1.76 to 4.15 ). This high risk could be explained by more sedentary lifestyle in urban areas as previously mentioned. In addition, in urban areas, eating patterns are different from that of rural areas with more sugar and fats rich food known as 'urban' or 'western' foods. ${ }^{8}$ Current tobacco consumption was inversely associated with the occurrence of overweight or obesity within both genders. Results from other studies reported that smoking for a long period tends to lead to weight loss. Similarly, cessation of tobacco consumption goes along with weight 


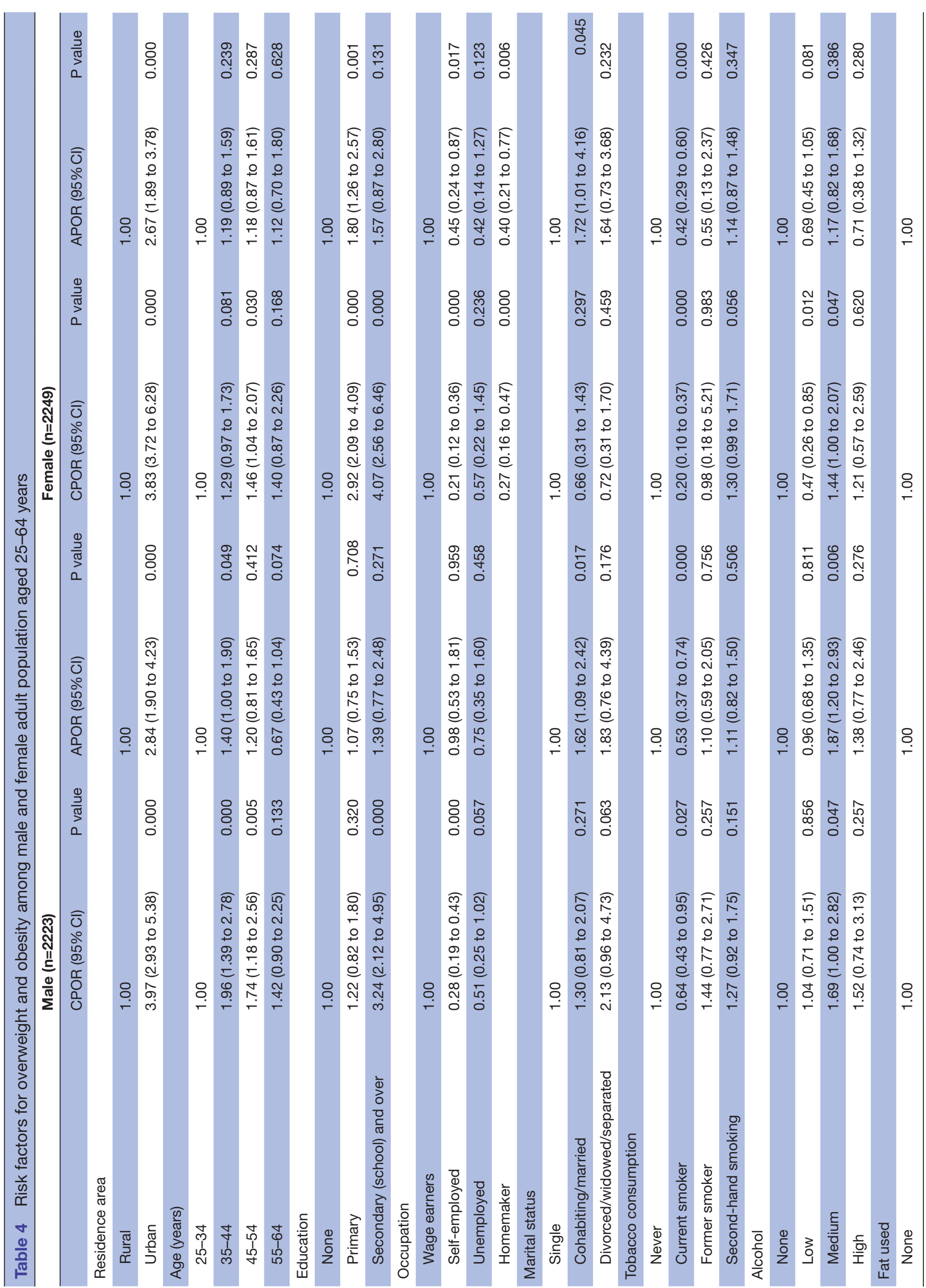


gain. ${ }^{38}{ }^{39}$ However, because smoking is an exposure with well-known detrimental consequences on health, the observed association between smoking and overweight/ obesity should not be interpreted as being in favour of smoking as a strategy to prevent obesity/overweight.

Other factors associated with overweight or obesity among men were age, marital status, consumption of butter/lard/margarine and physical activity. Several authors also reported a positive association between the risk of obesity and age. ${ }^{12} 1533$ Ageing leads to less physical activity, and when combined with greater socioeconomic status, increases the ability to access diverse foods. The use of butter/fat/margarine as the main source of lipid was inversely associated with obesity in our data. This is an unexpected result as one would expect a lower risk of overweight and obesity among those who use predominantly vegetable oil. The lack of quantification of the consumption of the different types of oils makes the comparison difficult. Physical activity was associated with significant decrease in the odds of obesity only in men and not in women in our data. Other studies carried out by Pasquet et al in Cameroon ${ }^{14}$ and Oladimeji et al in Nigeria ${ }^{16}$ revealed that the practice of intensive physical activity reduces significantly the risk of obesity.

Indeed, the intensive physical activity leads to an increase in the energy expenditure, avoids fat deposition and promotes a development of the muscular mass. ${ }^{40}$ Men living in union were about $60 \%$ more likely to be obese compared with single men. There was an association in the same direction in women. There is a correlation between marital status and socioeconomic position. In our study, we lack data on the socioeconomic status and we used education status as a proxy. Our findings of a positive correlation between being married and overweight/obesity may have been confounded by the socioeconomic status.

Among women, education was associated with obesity/ overweight. However, in their study among women living in urban areas, Benkeser et al in Ghana ${ }^{37}$ did not find a relation between educational level and obesity. This could be explained by the fact that their study was exclusively carried out in urban areas where the heterogeneity between educational statuses may be lesser. We found difference in predictors of overweight/obesity between men and women. Physical activity and age were significant predictors in men and not in women, while the education status and the type of employment were significant predictors in only women. These results are in favour of gender-specific predictors for overweight/obesity and are in support of gender-based stratified analyses.

\section{Limitations of the study}

The results reported in this study are derived from a crosssectional study limiting our ability to derive causal inferences from the observed associations. Exposures measurements were mainly based on a short window recall as it is usual in this type of studies, hampering the possibility to get further attributes (quantity, duration, etc) on some exposures such as fat and fruit consumptions, which would have been invaluable 
in the interpretation of the results. We did not have information on socioeconomic status that is a known key variable when trying to predict overnutrition. Furthermore, the analysis carried out and our interpretation of the results assume that an overweight person is in transition to obese status. While this is conceptually true, we cannot rule out that an overweight person will turn to be normal in the future, particularly in a setting where food insecurity is common.

\section{CONCLUSION}

Our study showed an important burden of obesity and overweight in the adult population with women more affected than men. Overnutrition needs to be recognised as an important public health issue. The country is witnessing the double burden of malnutrition with the coexistence of overnutrition and undernutrition. Nutrition interventions need to be reshaped to account for this epidemiological picture of malnutrition in Burkina Faso.

\section{Author affiliations}

${ }^{1}$ Epidemiology and Biostatistics, African Institute of Public Health, Ouagadougou, Centre, Burkina Faso

${ }^{2}$ National Tuberculosis Program, Ministry of Health, Ouagadougou, Burkina Faso ${ }^{3}$ Biomedicine and Public Health, Institut de Recherche en Sciences de la Sante, Ouagadougou, Centre, Burkina Faso

${ }^{4}$ East Health Regional Directorate, Ministry of Health, Fada N'Gourma, Burkina Faso ${ }^{5}$ National Institute of Public Health, Ministry of Health Burkina Faso, Ouagadougou, Centre, Burkina Faso

Acknowledgements This research was carried out by SKaboré as partial fulfilment of his master program in public health at the African Institute of Public Health. SKaboré was granted funds by the Ministry of Health of Burkina Faso for his master's program. The authors are grateful to the Ministry of Health for giving access to the data. We would also like to thank the African Institute of Public Health for the logistic support to the drafting of the article.

Contributors SKaboré, TM and SKouanda designed the study and SKaboré drafted the paper. SKabore and TM performed initial analysis and TM reanalysed the data. SKouanda, BB, JKS and HL made substantial contributions to the interpretation of the data. All authors read and approved the final manuscript.

Funding The authors have not declared a specific grant for this research from any funding agency in the public, commercial or not-for-profit sectors.

Competing interests None declared.

Patient and public involvement Patients and/or the public were not involved in the design, or conduct, or reporting, or dissemination plans of this research.

Patient consent for publication Not required.

Ethics approval The STEPS survey got approval from the Ethics Committee for Health Research (Deliberation No. 2012-12-092 of 05 December 2012). Written informed consent was obtained before inclusion in the study. For this study, we obtained an authorisation from the General Directorate of Health to reanalyse the data, and the confidentiality of study participants was preserved.

Provenance and peer review Not commissioned; externally peer reviewed.

Data availability statement Data are available upon reasonable request. The STEPS 2013 survey database was used for this study. The dataset can be obtained at the Ministry of Health upon reasonable request. Any request for further analysis can be submitted to BB (bicaba_brico@yahoo.fr). No further additional data are available.

Open access This is an open access article distributed in accordance with the Creative Commons Attribution Non Commercial (CC BY-NC 4.0) license, which permits others to distribute, remix, adapt, build upon this work non-commercially, and license their derivative works on different terms, provided the original work is properly cited, appropriate credit is given, any changes made indicated, and the use is non-commercial. See: http://creativecommons.org/licenses/by-nc/4.0/.

\section{ORCID iDs}

Tieba Millogo http://orcid.org/0000-0003-3548-3789

Seni Kouanda http://orcid.org/0000-0003-2426-7669

\section{REFERENCES}

1 Organisation mondiale de la Santé. Obésité [Internet]. WHO. World Health OrganizationWorld Health Organization. Available: https:// www.who.int/topics/obesity/fr/ [Accessed cité 3 août 2020].

2 World Health Organization. Obesity: preventing and managing the global epidemic. Geneva: World Health Organization, 2000.

3 DELPEUCH E, MAIRE B. Obesité et developpement des pays Du SUD. Med Trop 1997;57:380-8.

4 Ashkan A, Mohammad F, et al, GBD 2015 Obesity Collaborators. Health effects of overweight and obesity in 195 countries over 25 years. N Engl J Med 2017;377:13-27.

5 OMS. Obésité et surpoids [Internet]. WHO. Available: http://www.who.int/

6 Ali HM, Charbel El B, Ashkan A, et al. Burden of obesity in the eastern Mediterranean region: findings from the global burden of disease 2015 study. Int J Public Health 2018;63:165-76.

7 Melaku YA, Gill TK, Taylor AW, et al. Trends of mortality attributable to child and maternal undernutrition, overweight/obesity and dietary risk factors of non-communicable diseases in sub-Saharan Africa, 1990-2015: findings from the global burden of disease study 2015. Public Health Nutr 2019;22:827-40.

8 Zeba ANZ. Transition nutritionnelle et double fardeau de la malnutrition chez des adultes de Ouagadougou au Burkina Faso (Afrique de l'Ouest) [PhD]. Canada: Université de Montreal, 2012.

9 van der Sande MA, Bailey R, Faal H, et al. Nationwide prevalence study of hypertension and related non-communicable diseases in the Gambia. Trop Med Int Health 1997;2:1039-48.

10 Njelekela M, Ikeda K, Mtabaji J, et al. Obesity and other risk factors for cardiovascular diseases among Africans: results from cardiac study in Tanzania. Int Congr Ser 2004;1262:372-5.

11 Abubakari AR, Lauder W, Agyemang C, et al. Prevalence and time trends in obesity among adult West African populations: a metaanalysis. Obes Rev 2008;9:297-311.

12 Sagna Y. Obesity and Metabolic Syndrome in a Burkina Faso Urban Area: Prevalence,Associated Factors and Comorbidities. J Nutr Disorders Ther 2014;04.

13 Fezeu L, Minkoulou E, Balkau B, et al. Association between socioeconomic status and adiposity in urban Cameroon. Int $J$ Epidemiol 2005;35:105-11.

14 Pasquet P, Temgoua LS, Melaman-Sego F, et al. Prevalence of overweight and obesity for urban adults in Cameroon. Ann Hum Biol 2003;30:551-62.

15 Maruf FA, Udoji NV. Prevalence and socio-demographic determinants of overweight and obesity in a Nigerian population. J Epidemiol 2015;25:475-81.

16 Oladimeji AM, Fawole O, Nguku P, et al. Prevalence and factors associated with hypertension and obesity among civil servants in Kaduna, Kaduna state, June 2012. Pan Afr Med J 2014;18 Suppl 1:13.

17 Tene Marceline Y. Obesity, central obesity, overweight and diabetes: women are the most affected in Burkina Faso. $J$ Womens Health Care 2014;03.

18 Pessinaba S, Yayehd K, Pio M, et al. L'obésité en consultation cardiologique Lomé: prévalence et facteurs de risque cardio-vasculaire associés-étude chez 1200 patients. Pan Afr Med J 2013;12.

19 Mabiala-Babela J-R, Sabaye Alima J, Monabeka HG, et al. Profil épidémiologique et clinique de l'obésité de l'enfant Brazzaville (Congo). Cahiers de Nutrition et de 2011;46:259-62.

20 Koueta F, Dao L, Dao F, et al. Facteurs associés au surpoids et l'obésité des élèves de Ouagadougou (Burkina Faso). Santé 2011;21:5.

21 Kramoh KE, N'goran YNK, Aké-Traboulsi E, et al. Prévalence de l'obésité en milieu scolaire en Côte d'Ivoire. Annales de Cardiologie et d'Angéiologie 2012;61:145-9.

22 Msyamboza KP, Kathyola D, Dzowela T. Anthropometric measurements and prevalence of underweight, overweight and obesity in adult Malawians: nationwide population based Ncd steps survey. Pan Afr Med J 2013;15:108.

23 Institut National de la démographie. Recensement général de la population et de l'habitation de 2006. Burkina Faso, 2008: 52.

24 Santé Mdela. Projections démographiques de 20112020 des régions et districts sanitaires du Burkina Faso.

25 santé Mdela. Annuaire statistique 2014. Burkina Faso, 2015: 330. 
26 Santé Mdela. Rapport de l'enquete nutritionnelle nationale. 32. Burkina Faso, 2019.

27 Organisation mondiale de la Santé. Profils des pays pour les maladies non transmissibles (MNT), 2016.

28 Kish L. A procedure for objective Respondent selection within the household. J Am Stat Assoc 1949;44:380-7.

29 Millogo T, Bicaba BW, Soubeiga JK, et al. Diabetes and abnormal glucose regulation in the adult population of Burkina Faso: prevalence and predictors. BMC Public Health. déc 2018;18:350.

30 World Health Organization. Waist circumference and waist-hip ratio: report of a WHO expert consultation, Geneva, 8-11 December 2008. Geneva: World Health Organization, 2011.

31 Adebayo RA, Balogun MO, Adedoyin RA, et al. Prevalence and pattern of overweight and obesity in three rural communities in Southwest Nigeria. Diabetes Metab Syndr Obes 2014;7:153-8.

32 Kamadjeu RM, Edwards R, Atanga JS, et al. Anthropometry measures and prevalence of obesity in the urban adult population of Cameroon: an update from the Cameroon burden of diabetes baseline survey. BMC Public Health 2006;6:228.

33 Kirunda BE, Fadnes LT, Wamani H, et al. Population-Based survey of overweight and obesity and the associated factors in peri-urban and rural eastern Uganda. BMC Public Health 2015;15:1168.
34 Gomes A, Damasceno A, Azevedo A, et al. Body mass index and waist circumference in Mozambique: urban/rural gap during epidemiological transition. Obes Rev 2010;11:627-34.

35 Saeed KMI. Prevalence and associated risk factors for obesity in Jalalabad City - Afghanistan. Alex J Med 2015;janv.

36 Cai L, He J, Song Y, et al. Association of obesity with socioeconomic factors and obesity-related chronic diseases in rural Southwest China. Public Health 2013;127:247-51.

37 Benkeser RM, Biritwum R, Hill AG. Prevalence of overweight and obesity and perception of healthy and desirable body size in urban, Ghanaian women. Ghana Med J 2012;46:66-75.

38 Vander Weg MW, Klesges RC, DeBon M. Relationship between smokeless tobacco use and body weight in young adult military recruits. Nicotine Tob Res 2005;7:301-5.

39 Rodu B, Stegmayr B, Nasic S, et al. The influence of smoking and smokeless tobacco use on weight amongst men. J Intern Med 2004;255:102-7.

40 Tremblay A, Therrien F. Physical activity and body functionality: implications for obesity prevention and treatment. Can J Physiol Pharmacol 2006;84:149-56. 